\title{
BMJ Open How far are we from a medication use process aiming at well-informed adherent patients with long-term medications in Finland? Qualitative study
}

\author{
Niina Mononen (D) , ${ }^{1}$ Marika Pohjanoksa-Mäntylä, ${ }^{1}$ Marja SA Airaksinen, ${ }^{1}$ \\ Katri Hämeen-Anttila ${ }^{2}$
}

To cite: Mononen N, Pohjanoksa-Mäntylä M, Airaksinen MSA, et al. How far are we from a medication use process aiming at well-informed adherent patients with longterm medications in Finland? Qualitative study. BMJ Open 2020;10:e036526. doi:10.1136/ bmjopen-2019-036526

- Prepublication history and additional material for this paper are available online. To view these files, please visit the journal online (http://dx.doi. org/10.1136/bmjopen-2019036526).

Received 19 December 2019 Revised 30 March 2020 Accepted 19 May 2020

D) Check for updates

(C) Author(s) (or their employer(s)) 2020. Re-use permitted under CC BY-NC. No commercial re-use. See rights and permissions. Published by BMJ.

${ }^{1}$ Division of Pharmacology and Pharmacotherapy, Faculty of Pharmacy, University of Helsinki, Helsinki, Finland

${ }^{2}$ Assessment of

Pharmacotherapies, Finnish Medicines Agency Fimea, Helsinki, Finland

Correspondence to

Dr Niina Mononen;

niina.mononen@helsinki.fi

\section{ABSTRACT}

Objective Finland is one of the few countries that has established a national Medicines Information (MI) Strategy. The ultimate goal of the strategy is a well-implemented medication use process resulting in well-informed adherent patients. This study aimed at evaluating the implementation of the strategy 3 years after its launch. Design The evaluation applied a pragmatic approach and was conducted by interviewing stakeholders involved in the National MI Network enhancing the MI Strategy's implementation. The network comprises national key stakeholders producing and using MI. Data were deductively analysed according to the medication use process of the MI Strategy using the framework method, complemented with inductively derived categories.

Setting National implementation of the MI Strategy throughout the healthcare system after the first operational period (2012-2014) in 2015.

Participants The members of the National MI Network ( $n=79 / 111$, participation rate $71 \%$, representing $42 / 53$ stakeholder organisations).

Outcome measures A new conceptual framework was developed based on stakeholders' views on wellimplemented actions and actions needing development in the medication use process at (1) infrastructure (macro),

(2) healthcare professionals (meso) and (3) patient (micro) levels.

Results Medication counselling by community pharmacists was the primary implemented action, followed by physicians' actions while starting a new medication, and advice given by nurses. The major development needs concerned (1) poor access to patient information and its transfer in healthcare, particularly the lack of reconciled medication lists and electronic health records (macro); (2) poorly functioning medication use process in home care and social care units, such as nursing homes (meso); and (3) limited patient involvement in their care (micro).

Conclusions Far more actions for development than well-established practices in the medication use process were identified. Major challenges found in this evaluation are considered in the ongoing Rational Pharmacotherapy
Strengths and limitations of this study

- A wide range of stakeholders provided their reflections of the achievement of the ultimate goal of the national medicines information strategy 3 years after its launch.

- A majority of the stakeholder representatives were healthcare professionals, half of them being pharmacists, which may have skewed the results.

- Absence of real patients with chronic illnesses and medications may distort results.

- The dynamics of the interviews may have been influenced by the fact that they were conducted as individual, pair or group interviews according to the convenience of each stakeholder.

- In the conceptual model building, the breakdown of the data to macro, meso and micro levels assisted in constructing a holistic understanding of the medication use process and its development needs.

Action Plan 2018-2022 by the Ministry of Social Affairs and Health.

\section{INTRODUCTION}

Carrying out long-term medication is a collaborative process whereby the ultimate goal is well-informed patients who have the capability and motivation to self-manage their medications. Team-based and patient-centred care emphasises the roles and tasks of each healthcare provider involved in the care process to ensure medication use in a high-quality, safe, effective, economical and rational manner. ${ }^{1}$ Part of this collaborative team should be the patients themselves so that they can take responsibility for their own care and become empowered for self-management and selfcare. $^{2}$ Although all healthcare professionals involved in the medication use process should have clearly determined responsibilities and 
tasks, there still exists ambiguity in this respect..$^{3-5}$ Among healthcare professionals, there is uncertainty about their own roles and tasks, as well as those of other professionals. ${ }^{6-8}$ If the roles and tasks are not agreed on, it can lead to preventable risk situations, medication errors or omissions. ${ }^{3-11}$ It can also lead to a preventable increase in the medication-related burden for patients and impair their lived experience with the medication, ${ }^{12}$ for example, through inadequate support from the social and health service system at different phases of a long-term journey with a chronic illness. ${ }^{1314}$

Easy access to reliable and timely health and medicines information (MI) is an integral part of the successful medication use process for both healthcare providers and medicine users. ${ }^{15-21}$ This is a strategic issue which has been recognised by, for instance, the European Commission. ${ }^{1622}$ Finland is one of the few countries that has actually established a long-term strategic development plan for enhancing coordination between national key stakeholders involved in producing and using MI. ${ }^{17} 23-25$ In Finland, MI practices have been actively developed since the 1980s, especially in community pharmacies (online supplementary appendix A). ${ }^{26-30}$ Patients have a statutory right to receive information about their medicines from their healthcare providers, with physicians and pharmacists being mandated to counsel on safe and appropriate medicine use while prescribing and dispensing. ${ }^{31}{ }^{32}$ The current national medicines policy (2011-2020) prioritises the development of MI practices, particularly to improve coordination between MI providers and to enhance the use of MI sources in patient care. ${ }^{23}$ To implement these medicines policy actions, the Finnish Medicines Agency Fimea launched a national MI Strategy, 'Rational Use of Medicines through Information and Guidance', in 2012 with the ultimate goal of a well-implemented medication use process that will result in well-informed and adherent patients by $2020 .^{24} 25$ The special emphasis of the MI Strategy is on patients with long-term medications. Although stakeholders play a key role in the implementation of MI strategies, the implementation has not previously been evaluated from their perspective. ${ }^{17}$ The aim of this study was to evaluate the implementation of the MI Strategy in Finland from the stakeholders' perspective.

\section{METHODS}

\section{Key content of the MI Strategy}

The national MI Strategy was established by Fimea, which also coordinates its implementation. ${ }^{24}{ }^{25}$ The MI Strategy builds on the European Commission recommendations on MI to patients. ${ }^{16}$ The situation in other European Union (EU) countries was investigated by conducting an inventory of MI strategies in the EU countries in $2009{ }^{33}$ As the UK was found to have the most advanced and systematic MI practices within EU, their MI Strategy, 'Better Information, Better Choices, Better Health', was analysed in greater detail. ${ }^{34} 35$ To understand MI practices in Finland, an inventory of the MI research conducted in
Finland since 2000 was carried out to identify strengths and development needs in MI. ${ }^{28}{ }^{36}$ In addition, potential stakeholders to be involved in the national MI Strategy's implementation were interviewed to identify their views on strategic core contents and proposals for actions. ${ }^{25}$

The ultimate goal of the national MI Strategy was influenced by the chronic care model, ${ }^{37} 38$ which was quite extensively piloted in Finland in the beginning of the 2010s (ie, at the time the MI Strategy was established) as a potential basis for a new social and health services system. ${ }^{39}$ The model puts the patient at the centre and encourages the creation of structures and processes that the support self-management of chronic diseases. The model is applicable to MI as there is a wealth of evidence, both globally and from Finland, that patients do not receive adequate support to self-manage their medication, ${ }^{21} 40-43$ and adherence to treatment is still an unresolved issue. ${ }^{244-49}$

Online supplementary appendix B shows the modifications of the chronic care model used in the national MI Strategy. A key process for patients with long-term medications is the medication use process illustrated in online supplementary appendix B. The medication use process covers activities for the needs assessment for medication, selection of the medication and prescribing, dispensing, dosing and administration, patient motivation and counselling to support adherence and self-management, treatment follow-up and assessment of outcomes. ${ }^{24}$ The patient-specific medication plan is an important part of the medication use process, which facilitates implementation of the medication and communication on it between the patient and participating healthcare providers and organisations. This 'patient at the centre' model is also in line with the pharmaceutical care process introduced by the landmark article of Hepler and Strand in $1990 .^{50}$

The national MI Strategy has six main goals and 37 proposals for actions. ${ }^{24}$ Its implementation is divided into three operational periods (years 2012-2014, 2015-2017 and 2018-2020). The MI Strategy aims to (1) influence the quality, availability and use of MI targeted to consumers and healthcare professionals; (2) enhance professionals' MI training and competences; and (3) focus MI research to guide strategy work. Four working groups and their coordination group, that is, the National MI Network, form the primary resource for MI Strategy's implementation (see table 1). ${ }^{24} 25$

\section{Study design and setting}

The medicine use process with the patient at the centre (online supplementary appendix B) was chosen as a target of the national MI Strategy's evaluation. The study applied a pragmatic approach, and the evaluation was based on the reflections of the members of the National MI Network. A qualitative cross-sectional design with semistructured interviews among the members of the MI Network was used. The interviews were performed after the first 3-year operational period (2012-2014) of the national MI Strategy in 2015. During this operational 
Table 1 Characteristics of the individual stakeholder representatives $(n=79)$ and the stakeholder organisations $(n=42)$ participating in the study ( $n=$ number of individual stakeholder representatives or stakeholder organisations)

\begin{tabular}{|c|c|c|c|c|}
\hline \multirow[b]{2}{*}{ Stakeholders by profession } & \multicolumn{2}{|c|}{$\begin{array}{l}\text { Individual stakeholder } \\
\text { representatives who } \\
\text { participated in the study }\end{array}$} & \multicolumn{2}{|c|}{$\begin{array}{l}\text { Individual stakeholder } \\
\text { representatives in the MI } \\
\text { Network* }\end{array}$} \\
\hline & $\mathbf{n}$ & $\%$ & $\mathbf{n}$ & $\%$ \\
\hline Pharmacists & 34 & 43.0 & 41 & 36.9 \\
\hline Physicians & 17 & 21.5 & 22 & 19.8 \\
\hline Nurses & 12 & 15.2 & 15 & 13.5 \\
\hline Others & 11 & 13.9 & 21 & 18.9 \\
\hline Practical nurses & 2 & 2.5 & 2 & 1.8 \\
\hline Healthcare students & $1 \dagger$ & 1.3 & $4 † \ddagger \S \rrbracket$ & 3.6 \\
\hline Dentists & 0 & 0 & 1 & 0.9 \\
\hline Not known & 2 & 2.5 & 5 & 4.5 \\
\hline Altogether & 79 & & 111 & \\
\hline \multirow[t]{2}{*}{ Stakeholders by type of affiliation } & \multicolumn{2}{|c|}{$\begin{array}{l}\text { Stakeholder organisations that } \\
\text { participated in the study }\end{array}$} & \multicolumn{2}{|c|}{$\begin{array}{l}\text { Stakeholder organisations } \\
\text { represented in the MI Network }\end{array}$} \\
\hline & $\mathrm{n}$ & $\%$ & $\mathrm{n}$ & $\%$ \\
\hline $\begin{array}{l}\text { Healthcare centres, hospitals and hospital districts, } \\
\text { hospital pharmacies and dispensaries, and university } \\
\text { pharmacies }\end{array}$ & 8 & 19.0 & 8 & 15.1 \\
\hline Patient associations and organisations & 8 & 19.0 & 10 & 18.9 \\
\hline Professional organisations & $7 \dagger \S \rrbracket$ & 16.7 & 8†‡§ף & 15.1 \\
\hline Universities & $6 † \S \rrbracket$ & 14.3 & $6 † \S \rrbracket$ & 11.3 \\
\hline Scientific societies & $4 \dagger \S^{* *}+\dagger$ & 9.5 & $5+\S \rrbracket^{\star *}$ & 9.4 \\
\hline Polytechnics and vocational institutions & $39 \neq \ddagger$ & 7.1 & 5 5㧊 & 9.4 \\
\hline National authorities & 2 & 4.8 & 3 & 5.7 \\
\hline Organisations representing pharmaceutical industry & 2 & 4.8 & 2 & 3.8 \\
\hline Continuing education units & $1 \dagger$ & 2.4 & $1 \dagger$ & 1.9 \\
\hline Student associations & $1 \dagger$ & 2.4 & $4 † \ddagger \S \bigoplus$ & 7.5 \\
\hline Others & 0 & 0 & 1 & 1.9 \\
\hline Altogether & 42 & & 53 & \\
\hline
\end{tabular}

*National MI Network.

†Pharmacy.

fDentistry.

§Medicine.

१Nursing.

${ }^{* *}$ Clinical pharmacology.

††Psychiatry.

$\ddagger \ddagger$ Pratical nursing.

MI, Medicines Information.

period, the MI Network had 111 members representing 53 stakeholder organisations. First, an invitation to participate in the interview was sent to all members of the MI Network via email. Following this, a more detailed information letter was sent to those who agreed to participate in the study.

\section{Interview guide}

A semistructured interview guide with two main themes and eight subthemes focusing on the goals and actions of the national MI Strategy was developed. ${ }^{24}$ The interview guide was pretested in two pilot interviews with six participants. No significant changes were made based on the pilot, and therefore, the data from the pilots were included in the study. The two main themes discussed in the interviews pertained to (1) reaching the goals and implementing the actions of the MI Strategy and (2) actions taken by the National MI Network. This study focused on the first main theme and the following questions in the interview guide: 'If you consider the figure of medication use process for a patient with chronic 


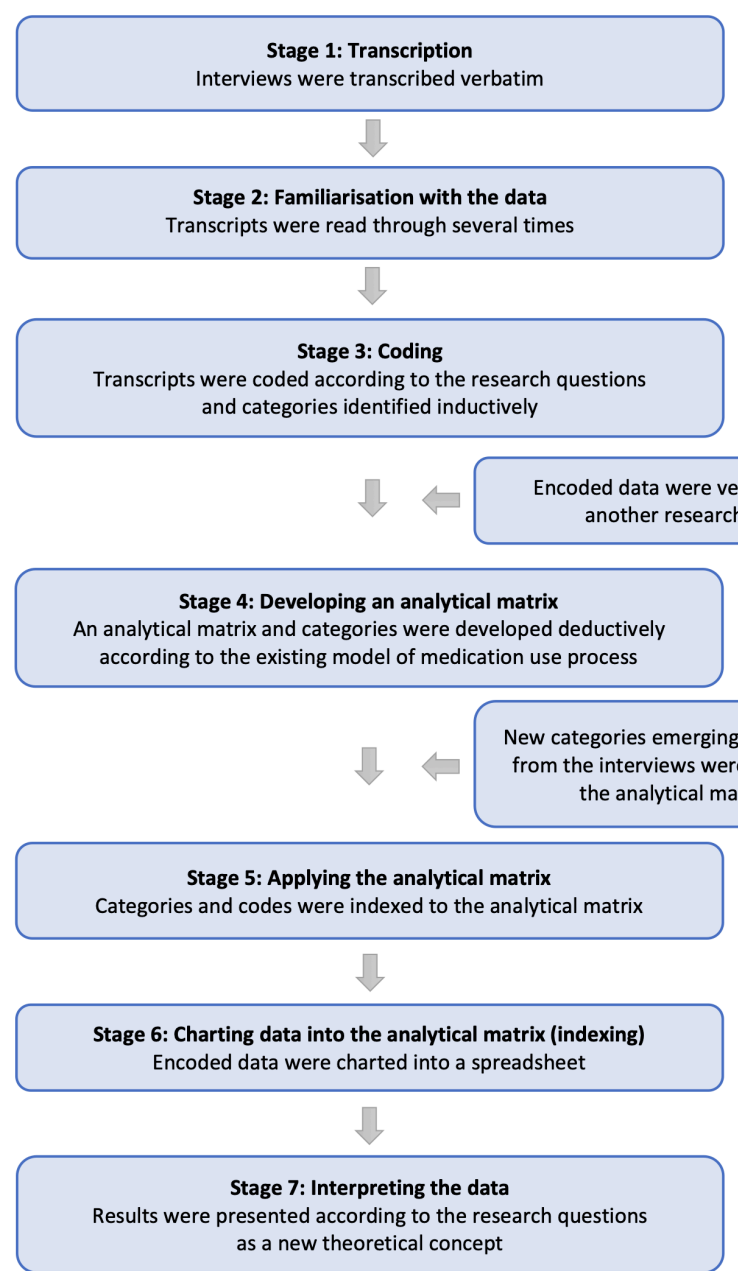

Figure 1 Content analysis process applying the framework method. ${ }^{51}$

diseases, then (1) what are the most crucial actions that have been implemented, and (2) what actions should be focused on in the future in order to achieve the goal of a well-informed, adherent patient or medicine user?' The figure of the medication use process as illustrated in the MI Strategy was shown to the participants to stimulate discussion during the interview (online supplementary appendix B). ${ }^{24}$

\section{Data collection}

Interviews were conducted as individual, pair and group interviews, depending on the individual preference of each stakeholder in 2015 . The aim was to have only one stakeholder organisation in each interview. Due to the geographical location and schedules of the participants, interviews were conducted face-to-face, by telephone or via video conferencing. One moderator (NM, a female pharmacist, MSc, with training in qualitative interviews) facilitated and audiotaped all interviews with permission from the participants.

\section{Analysis}

Data were analysed by applying the framework method, which uses both deductive and inductive content analysis (figure 1). ${ }^{51}$ The analysis was carried out in stages using Microsoft Word and Excel (Windows V.10 Home). The interviews were transcribed verbatim by a company specialising in converting to written text qualitative research data (stage 1). Each transcript was repeatedly read by one researcher (NM) while listening to the audiotapes (stage 2). Single words, sentences or groups of sentences related to study questions were coded by one researcher (NM) and verified by another researcher (MPM) (stage 3). Any differences in interpretation were discussed with the research group and consensus was received. Once the key categories were identified inductively, the transcripts were purposively read to detect any discussion that deviated from these categories, and an analytical matrix was developed (stage 4). Main and subcategories were primarily developed deductively according to the medication use process previously published in the national MI Strategy (online supplementary appendix B) ${ }^{24}$ (stage 5). Additionally, new main and subcategories were inductively derived from the interview data. Codes were classified into main categories, and the encoded data were charted into a spreadsheet generated from the analytical matrix (stage 6). Based on the existing medication use process model (online supplementary appendix B) and complemented by participants'views identified from the interviews, a new conceptual framework of the medication use process was developed (stage 7). The results are presented in accordance with two main research questions, that is, stakeholders' views on (1) the well-implemented actions and (2) the actions needing development in the medication use process. The results are classified into three operational levels: infrastructure (macro), healthcare professional (meso) and patient (micro) levels. This follows the conceptual framework applied to combine the functions of primary care with the dimensions of integrated care. $^{52}$ Numbers of encodings were counted according to the mentions by each participant, and the summative numbers were set into the operational levels. The standards for reporting qualitative research was used when applicable. $^{53}$

\section{Ensuring rigour of the analysis}

In the conceptual model building, breakdown of the data to macro, meso and micro levels was used. ${ }^{52}$ Trustworthiness of the analysis process was confirmed in every phase, including data preparation (eg, verbatim transcripts), management of data (eg, software was used in data coding) and reporting of results (eg, a single coder with a reviewer). ${ }^{545}$ To ensure the credibility, a previously known model of a medication use process ${ }^{24}$ was used as an analysis matrix, supplemented with the main and subcategories identified inductively from the data. Additionally, a theoretical method previously used in healthcare research $^{52}$ was applied in analysing data to strengthen credibility. To increase the comprehensivity of the study, two researchers - and when necessary the whole research group - were involved in the data analysis process. The content and structure of concepts created by content 
analysis were illustrated with the examples of quotations from various participants to indicate conformability and objectivity. Quotations have been selected to represent the identified main and subcategories in the new conceptual framework developed for the medication use process.

\section{Research ethics}

The study was conducted according to good scientific practice, following the guidelines of the Finnish Advisory Board on Research Integrity. ${ }^{56}$ According to the guidelines, the study was deemed to be exempt from requiring approval from the research ethics committee. The research plan was approved by the National MI Network before starting the data collection. Prior to the interviews, participants were informed in writing about the study and that the interviews will be tape-recorded. At the beginning of each interview, they were asked to give informed consent. Participation was voluntary with the opportunity to withdraw from the study at any time. The recordings and interview notes were digitally stored and encrypted with a password. All data were anonymised and were accessible only to the authors. Privacy and confidentiality of the individuals participating in the study were ensured throughout the entire research project.

\section{Patient and public involvement}

Patient participation was taken into account by interviewing representatives from various national patient organisations who were active partners in the National MI Network. There was no real patients or public involvement in the planning phase or design of the study. The results of the study will be discussed in the MI Network for further actions of the national MI Strategy that will be extended to a new term lasting until 2026.

\section{RESULTS}

In total, 79 out of 111 members of the National MI Network participated in the study (participation rate $71 \%$ ), representing 42 out of 53 stakeholders (table 1 ). Women represented $77 \%(\mathrm{n}=61)$ of participants. Interviews $(n=43)$ were conducted as individual $(n=22)$, pair $(\mathrm{n}=11)$ or group interviews $(\mathrm{n}=10)$, either face-to-face $(79 \%, \mathrm{n}=34)$, by telephone $(12 \%, \mathrm{n}=5)$, as video conferencing $(7 \%, \mathrm{n}=3)$, or as face-to-face and video conferencing $(2 \%, \mathrm{n}=1)$. Altogether, 3-6 participants attended the group interviews at a time. Four interviews included participants from more than one stakeholder organisation. A majority of the participants were pharmacists ( $43 \%$ of all participants, $\mathrm{n}=34$ ), physicians $(22 \%, \mathrm{n}=17)$ and nurses $(15 \%, \mathrm{n}=12)$. Educational units were the most commonly represented stakeholder group (24\% of the stakeholder organisations, $\mathrm{n}=10$ ), including universities, polytechnics, vocational institutions and continuing education units.

\section{Well-implemented actions in the medication use process}

The new conceptual framework illustrating wellimplemented actions in the medication use process consisted of 10 main categories of actions (figures 2 and $3)$. Of these, seven were derived deductively from the previous medication use process model (online supplementary appendix B), and three were inductively derived from the data (figure 3). All the inductively derived

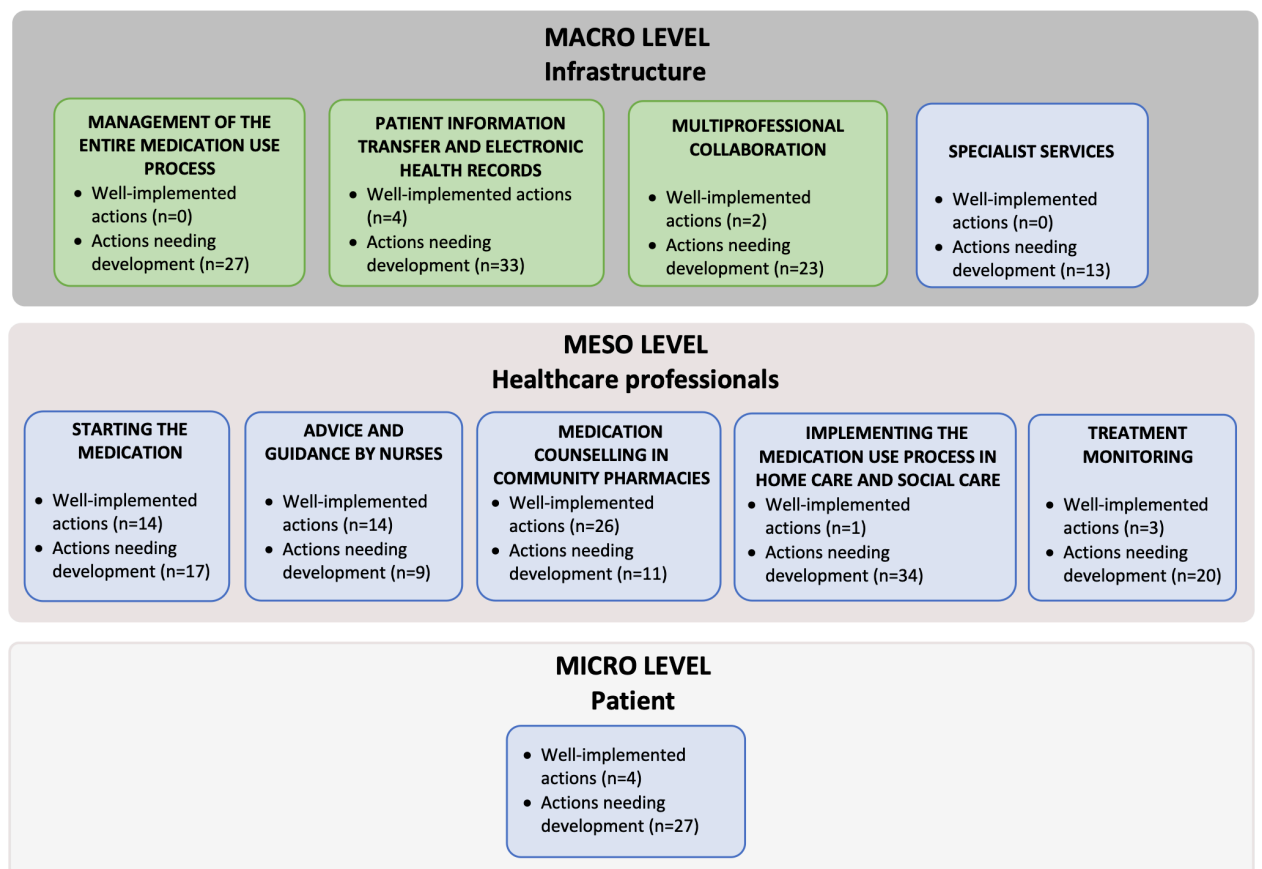

Figure 2 Categories of themes derived deductively (marked as blue) and inductively (marked as green) from the stakeholders' interviews ( $n=42$, involving 79 interviewees) on well-implemented actions and actions needing development in medication use process for patients with chronic illnesses ( $n=a$ summative of the number of the single interviewee's mentions). 


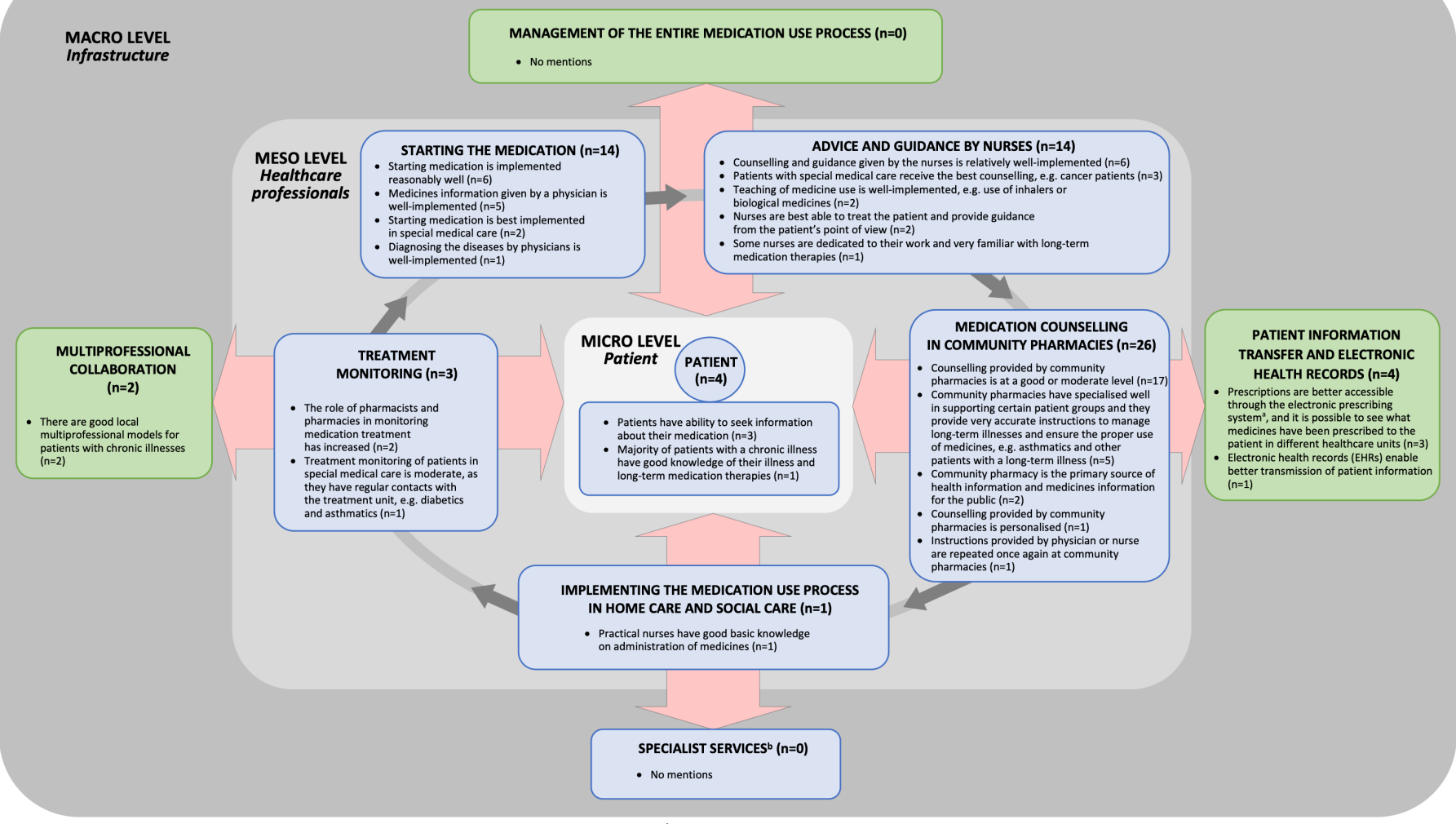

Figure 3 Stakeholders views on well-implemented actions in medication use process for patients with chronic illnesses. Categories derived deductively are marked as blue $(n=7)$, and categories that emerged inductively from the stakeholders' interviews are marked as green $(n=3)\left(n=a\right.$ summative of the number of the single interviewee's mentions). ${ }^{a}$ All prescriptions must be electronically prescribed from 1 January 2017 ; ${ }^{\mathrm{b}}$ for example, clinical pharmacology consultation services and comprehensive medication reviews. HCP, healthcare professional.

categories were at the infrastructure ( macro) level. Around half of the participants $(52 \%)$ reported well-implemented actions, mostly at the meso level (ie, healthcare professionals). Of these actions, medication counselling by community pharmacists was considered the best implemented ( $\mathrm{n}=26$ mentions), followed by physicians' performance while starting a medication $(\mathrm{n}=14)$, and advice and guidance provided by nurses $(\mathrm{n}=14)$ (online supplementary appendix $\mathrm{C}$ ).

Very few mentions of the well-implemented actions at the infrastructure (macro) level were present (figure 3). These related to the patient information transfer and electronic health records (EHRs) $(\mathrm{n}=4$ mentions of being well-implemented) and multiprofessional collaboration $(n=2)$, while none of the stakeholders mentioned management of the entire medication use process $(n=0)$ or specialist services $(\mathrm{n}=0)$ as well-implemented.

\section{Actions needing development in the medication use process}

The stakeholders mentioned far more actions for development than well-established practices in the medication use process (211 vs 68 mentions, respectively) (figures 2-4). Almost all participants (94\%) raised at least one area for improvement (figures 2 and 4 and online supplementary appendix $\mathrm{C}$ ). The highest number of mentions indicating a need for development concerned medication use process in home care and social care (meso) $(\mathrm{n}=34)$, patient information transfer and EHRs, including reconciled medication lists (macro) $(\mathrm{n}=33)$, and patients' management with the medication (micro) $(\mathrm{n}=27)$. At the infrastructure (macro) level, management of the entire medication use process $(\mathrm{n}=24)$ and multiprofessional collaboration $(n=23)$ were also frequently mentioned as areas for development.

In the medication use process in home care and social care units, such as nursing homes, most of the concerns related to skills, competences and inadequate training of practical nurses to appropriately manage the medications of their older clients (figure 4). A need for additional training in pharmacotherapy was raised, particularly for home care and nursing home staff to meet the requirements of their current work duties in geriatric care. Inadequate patient information transfer between care units and limited availability of EHRs in the medication use process were among the major concerns as not all professionals involved in the care team have access to complete and accurate patient information, such as laboratory results, or when the patient is transferred from a care unit to another. In addition, many stakeholders reported that the management of the entire medication use process needed development, indicating fragmentation, lack of 


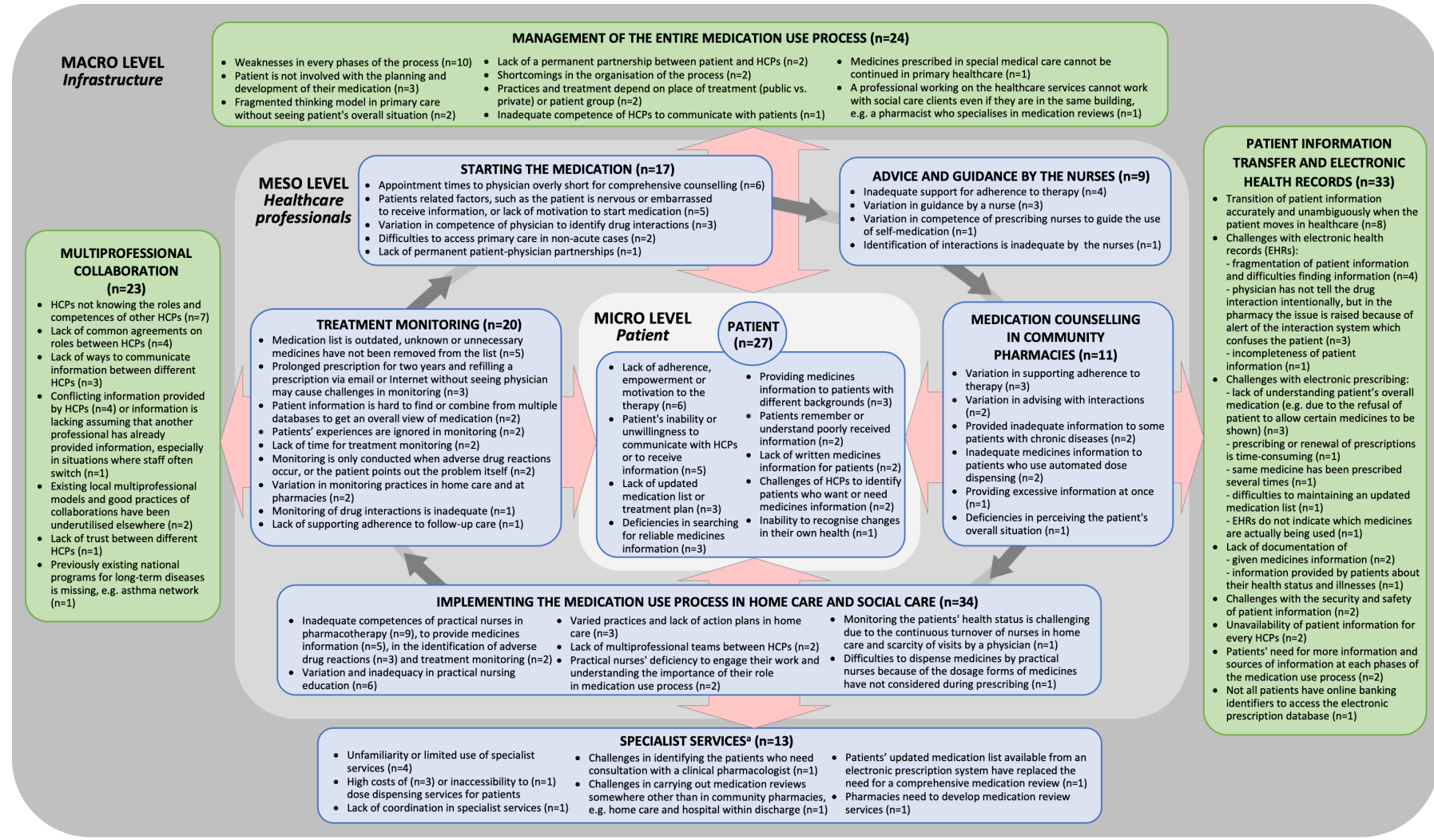

Figure 4 Stakeholders' views on actions needing development in medication use process for patients with chronic illnesses. Categories derived deductively are marked as blue $(n=7)$, and categories that emerged inductively from the stakeholders' interviews are marked as green $(n=3)\left(n=a\right.$ summative of the number of the single interviewee's mentions. ${ }^{2}$ For example, clinical pharmacology consultation services and comprehensive medication reviews. HCP, healthcare professional.

coordination and poor collaboration between different healthcare professionals and between professionals and patients. They also expressed concerns on treatment monitoring as it was not commonly conducted very systematically.

Finally, poor patient involvement during the entire medication use process was a concern reflecting a lack of motivation or adherence to treatment and an inability or unwillingness to communicate with healthcare professionals (figure 4). A further concern was that patients do not always have reconciled medication lists or treatment plans, which may challenge not only healthcare professionals at the point of prescribing and dispensing medicines but also patients while using medicines at home. Additionally, patients' limited skills in searching reliable health and MI and insufficient medication counselling for particular patient groups, such as the deaf and people with vision impairment and using multiple medications, were identified as areas needing attention.

\section{DISCUSSION}

This study revealed that the medication use process of chronically ill patients using long-term medications requires development at every level of implementation. The major development needs in the infrastructure concern the coordination and management of care, transfer of patient information between care units, availability of a reconciled medication list, and local and national agreements on the responsibilities of patients and professionals involved in the medication use process. The most urgent development needs at the professional level focus on the entire medication use process in primary and social care, particularly in geriatric units where practical nurses' competences do not meet their actual work responsibilities. The current medication use process lacks genuine patient-centeredness, manifested by a lack of adherence, motivation and communication, and the inability of patients to retrieve information. Patients on long-term medications need to be better involved in implementing their treatment by improving empowerment and partnership, and by finding new ways to support self-management and treatment commitment.

According to the stakeholders, challenges in implementing the medication use process appear to be the greatest in primary care, especially in home care and social care units such as in nursing homes. This means social and healthcare units providing care for older adults in the poorest health conditions. The result may reflect that the Finnish population is ageing rapidly and the care system has not been adequately prepared for the growing need, for example, to train care personnel in geriatric pharmacotherapy to safely manage the medications. This is particularly the case for practical nurses whose responsibility for medication management in geriatric care 
units has increased remarkably even though their pharmacotherapy training is limited. Practical nurses have 3-year vocational education that focuses on supportive and technical nursing, and, thus, they may not have adequate competence to take responsibility for medication. This finding is in line with previous studies showing that nursing personnel (eg, practical nurses) working in home care and social welfare units may also lack pharmacotherapy knowledge and skills in providing MI. ${ }^{28} 57-60$ The same trend and challenges have been found in other research and development programmes in Finland and other countries. ${ }^{5758}$ The challenge of safe management of medications and polypharmacy of older adults has been prioritised globally in the ongoing WHO Global Patient Safety Programme 'Medication Without Harm' ${ }^{61}$ Further research should focus on geriatric care units in primary and social care to better understand the systems-based root causes and contributing factors of actual and potential risks in the current medication use processes.

Despite the pharmaceutical policy initiatives and wide recognition internationally of the importance of patient empowerment and involvement in healthcare, ${ }^{2} 61$ our study reflects that it might not be actualised in the best possible way. It is worth remembering that the majority of the interviewees in this study were health professionals, even in cases they represented the voice of patients. Thus, the results are skewed to a professional opinion even in the patient perspective. Nevertheless, the results send a clear message that patients' involvement in their longterm medication should be significantly increased. To be successful, research and actions should focus on a patient approach in the implementation of long-term medications. Only the patients themselves can describe the issues that matter to them, affecting their motivation for treatment, success of self-management and empowerment. Future studies should focus on real patients to explore their perceptions and experiences.

In this study, the stakeholders reported that patients are not often willing to discuss their medications and medication-related problems. This may reflect their preferences, or capacity for participation, or uncertainty about the responsibilities and tasks of patients' and different healthcare professionals in the medication use process. A communicative relationship between healthcare professionals and patients is an essential driver for patient involvement in the medication use process, and for motivation for self-management and empowerment with medication use, especially for those with long-term medications. ${ }^{37} 385062-64$ Healthcare professionals should encourage patients to share experiences and concerns about their treatment. They also need to ensure access to MI throughout the process. Although the number of MI sources available for patients has increased, people might not always receive MI from any sources. ${ }^{16} 1722$ In Finland, the proportion of patients who report not receiving information on medicines they use from any healthcare professional has more than doubled between 1999 and 2014. ${ }^{21}$ Actions are needed to ensure equal access of MI for all patients and throughout the medication use process to support self-management and empowerment.

Infrastructural factors leading to poor access to patient and MI and poor adherence, such as a lack of reconciled medication lists and treatment plans, and lack of personal communication with care providers should be further investigated from a patient perspective. ${ }^{1365}$ In particular, a reconciled medication list is essential for professionals and patients. For example, guidelines for patient-centred therapeutic counselling assume that the practitioner should review available patient information before the encounter and use the information gathered to determine what to discuss and agree on the treatment with the medicine user. ${ }^{28} 3066$

Since this evaluation was conducted in 2015, shortcomings found in the infrastructure of the medication use process related to the coordination and availability of EHRs have been recognised in the ongoing Rational Pharmacotherapy Action Plan 2022. ${ }^{62}$ The government programme ${ }^{67-69}$-based action plan is intended to strengthen the actions at the infrastructure level, which were minor in 2015. At the same time, it extends the scope of development towards the meta level, including health and medicines policy-making that can facilitate infrastructural changes in the medication use process through information guidance, resource allocation and legislation. $^{70}$

\section{Strengths and limitations of this study}

This pragmatic evaluation was carried out at an early stage of national MI Strategy's implementation. The aim was to conduct an evaluation by interview in order to obtain more detailed information from the stakeholders than would have been obtained, for example, through a survey. The interviews covered the whole range of stakeholders actively involved in implementing the MI Strategy. They can be assumed to be informants with the best understanding of the topic of research. However, the majority of the stakeholder representatives were healthcare professionals, half of them being pharmacists, which may have skewed the results. There was also an absence of real patients with chronic illnesses and medications, which may also distort results. The dynamics of the interviews may have been influenced by the fact that they were conducted as individual, pair or group interviews according to convenience of each stakeholder. The data from different types of interviews were combined, and the relative power of the opinions was determined by counting the mentions for each action. The profession or stakeholder group was not specified during the analysis, as the aim was to obtain an overall understanding of the implementation of the medication use process rather than to compare views between professions or stakeholders. Moreover, participants' demographics, except gender, were not collected. The figure of the medication use process (online supplementary appendix B) was an important tool in the interviews to keep the discussion focused on core issues. Furthermore, the figure was also 
used as a framework in the deductive analysis, which was supplemented with an inductive analysis of the interview data. Thus, the figure was the basis for conducting the study, and it has a strong influence on the study findings.

\section{Implications and future research}

This has been an eye-opening study that has helped us to understand the functionality and shortcomings of the entire medication use process. The theory-based, conceptual model and methodology applied in this study may be useful for future follow-up evaluations or for evaluating medication use processes in other settings. The key shortcomings highlighted by the stakeholders have formed the core of the Rational Pharmacotherapy Action Plan 2018-2022. ${ }^{62}$ Actions are under way to improve the coordination and management of medication use process, for example, by launching a reconciled medication list, and to increase patient engagement and partnership in their care. The Action Plan was based on the government programme 2015-2019, still being supported by the current programme as part of the ongoing social and health services reform. ${ }^{67-69}$ Thus, it has a strong mandate to change the medication use process. Such long-term strategies as 'Partnership in Medicine Taking' in the UK provide good practices to be benchmarked. ${ }^{71}$ The chronic care model is still a valid theoretical framework for getting the patient at the centre. ${ }^{3738}$

Future research should focus on investigating the root causes for poor patient involvement in their own care. To improve medication adherence, the medication use process should be developed on a patient-oriented basis. This requires more qualitative research that listens to the long-term patients' experiences and modifies the medication use process accordingly. The implementation of the medication use process should be further studied in different patient groups, as also suggested by the Rational Pharmacotherapy Action Plan. ${ }^{62} 65$ The most urgent need in this respect concerns older people who are at the highest risk of medication-related harm, particularly in primary care and social care institutions. Research should focus on enhancing coordination of care and improving usability of electronic systems supporting the implementation of medication use processes databases and systems. ${ }^{5} 72$

\section{CONCLUSIONS}

Weaknesses in the infrastructure of the medication use process reflecting the transfer of patient information, poorly functioning medication use processes in primary care and limited participation of patients in their care are priority areas while implementing the next steps of the national MI Strategy are found. Many of the challenges identified in this evaluation have been taken into consideration in the MI Strategy's implementation since 2015; the major challenges are also in the Rational Pharmacotherapy Action Plan 2018-2022 by the Ministry of Social Affairs and Health.
Acknowledgements The authors gratefully acknowledge the members of the National Medicines Information Network who participated in this study. The authors acknowledge the Elli Turunen Fund of the Finnish Cultural Foundation for providing funding. The authors warmly thank Perihan Ipek for assistance in collecting the data, and AMNielsen ApS and Chelsea Schneider for proofreading the manuscript.

Contributors NM, MSAA, MP-M and KH-A were involved in designing the study, developing the interview guide, planning the analysis and reporting this particular study. NM performed the interviews and data analysis. MP-M verified the codings of the data. MSAA, MP-M and KH-A contributed in the interpretation of the data. NM prepared the initial draft of the manuscript. MSAA, MP-M and KH-A critically reviewed and revised the manuscript. All authors read and gave the final approval of the version to be published.

Funding This research was supported by the Elli Turunen Fund of the FinnishCultural Foundation. The sponsors had no role in the design and conduct of the study; collection, management, analysis and interpretation of the data; or in tje preparation, review or approval of the manuscript.

Competing interests None declared.

Patient consent for publication Not required.

Provenance and peer review Not commissioned; externally peer reviewed.

Data availability statement No data are available.

Open access This is an open access article distributed in accordance with the Creative Commons Attribution Non Commercial (CC BY-NC 4.0) license, which permits others to distribute, remix, adapt, build upon this work non-commercially, and license their derivative works on different terms, provided the original work is properly cited, appropriate credit is given, any changes made indicated, and the use is non-commercial. See: http://creativecommons.org/licenses/by-nc/4.0/.

ORCID iD

Niina Mononen http://orcid.org/0000-0001-7846-3492

\section{REFERENCES}

1 World Health Organization. Innovative care for chronic conditions: building blocks for actions. Gobal report. World Health Organization, 2002. Available: https://www.who.int/chp/knowledge/publications/ icccglobalreport.pdf?ua=1 [Accessed 10 Dec 2019].

2 World Health Organization. Adherence to long-term therapies: evidence for action. World Health Organization, 2003. Available: www.who.int/chp/knowledge/publications/adherence_report/en/ [Accessed 10 Dec 2019].

3 Celio J, Ninane F, Bugnon O, et al. Pharmacist-nurse collaborations in medication adherence-enhancing interventions: a review. Patient Educ Couns 2018;101:1175-92.

4 Olsen CF, Bergland A, Debesay J, et al. Striking a balance: health care providers' experiences with home-based, patient-centered care for older people-A meta-synthesis of qualitative studies. Patient Educ Couns 2019;102:1991-2000.

5 Toivo T, Dimitrow M, Puustinen J, et al. Coordinating resources for prospective medication risk management of older home care clients in primary care: procedure development and RCT study design for demonstrating its effectiveness. BMC Geriatr 2018;18:74.

6 Elvey R, Hassell K, Hall J. Who do you think you are? pharmacists' perceptions of their professional identity. Int J Pharm Pract 2013;21:322-32.

7 Kusi-Appiah E, Dahlke S, Stahlke S. Nursing care providers perceptions on their role contributions in patient care: An integrative review. J Clin Nurs 2018;27:3830-45.

8 Lawrence RA, McLoone JK, Wakefield CE, et al. Primary care physicians' perspectives of their role in cancer care: a systematic review. J Gen Intern Med 2016;31:1222-36.

9 Berland A, Bentsen SB. Medication errors in home care: a qualitative focus group study. J Clin Nurs 2017;26:3734-41.

10 Teinilä T, Kaunisvesi K, Airaksinen M. Primary care physicians perceptions of medication errors and error prevention in cooperation with community pharmacists. Res Social Adm Pharm 2011;7:162-79.

11 van Sluisveld N, Zegers M, Natsch S, et al. Medication reconciliation at hospital admission and discharge: insufficient knowledge, unclear task reallocation and lack of collaboration as major barriers to medication safety. BMC Health Serv Res 2012;12:170.

12 Mohammed MA, Moles RJ, Chen TF. Medication-Related burden and patients' lived experience with medicine: a systematic review and metasynthesis of qualitative studies. BMJ Open 2016;6:e010035. 
13 Kekäle M. Chronic myeloid leukemia patients' adherence to tyrosine kinase inhibitors in Finland: A journey of eighty-six patients [dissertation]. University of Helsinki, 2016. http://urn.fi/URN:ISBN: 978-951-51-2353-4

14 Puspitasari HP, Aslani P, Krass I. Pharmacists' and consumers' viewpoints on counselling on prescription medicines in Australian community pharmacies. Int J Pharm Pract 2 010;18:202-8.

15 Chisholm-Burns MA, Kim Lee J, Spivey CA, et al. Us pharmacists' effect as team members on patient care: systematic review and meta-analyses. Med Care 2010;48:923-33.

16 European Commission. High level pharmaceutical forum 2005-2008: conclusions and recommendations. European communities, 2008. Available: https://publications.europa.eu/en/publication-detail/-/ publication/4fddf639-47cc-4f90-9964-142757d2515a [Accessed 10 Dec 2019].

17 International Pharmaceutical Federation. Medicines information: strategic development. The Hague: International Pharmaceutical Federation, 2017. www.fip.org/www/streamfile.php?filename=fip/ publications/2017-01-Medicines-information-strategic-development. pdf

18 Ryan R, Santesso N, Lowe D, et al. Interventions to improve safe and effective medicines use by consumers: an overview of systematic reviews. Cochrane Database Syst Rev 2014:CD007768.

19 Van Camp YP, Van Rompaey B, Elseviers MM. Nurse-Led interventions to enhance adherence to chronic medication: systematic review and meta-analysis of randomised controlled trials. Eur J Clin Pharmacol 2013;69:761-70.

20 Zolnierek KBH, Dimatteo MR. Physician communication and patient adherence to treatment: a meta-analysis. Med Care 2009;47:826-34.

21 Mononen N, Airaksinen MSA, Hämeen-Anttila K, et al. Trends in the receipt of medicines information among Finnish adults in 19992014: a nationwide repeated cross-sectional survey. BMJ Open 2019;9:e026377.

22 European Commission. High level group on innovation and provision of medicines in the European Union: recommendations for action. G10 medicines report. European Communities, 2002. http://ec. europa.eu/health/ph_overview/Documents/key08_en.pdf

23 Ministry of social Affairs and health. Medicines policy 2020: towards efficient, safe, rational and cost effective use of medicines. Publications of the Ministry of Social Affairs and Health, 2011. http:// urn.fi/URN:ISBN:978-952-00-3165-7

24 Finnish Medicines Agency Fimea. Rational use of medicines through information and guidance - medicines information services: current state and strategy for 2020. Serial Publication Fimea Develops, Assesses and Informs, 2012. http://urn.fi/URN:ISBN:978-952-562421-2

25 Hämeen-Anttila K, Luhtanen S, Airaksinen M, et al. Developing a national medicines information strategy in Finland - a stakeholders' perspective on the strengths, challenges and opportunities in medicines information. Health Policy 2013;111:200-5.

26 Airaksinen $M$, Ahonen R, Enlund $\mathrm{H}$. The "questions to ask about your medicines" campaign. An evaluation of pharmacists' and the public's response. Med Care 1998;36:422-7.

27 Kansanaho H. Implementation of the principles of patient counselling into practice in Finnish community pharmacies [dissertation]. University of Helsinki, 2006. http://urn.fi/URN:ISBN:952-10-2877-7

28 Mononen N, Järvinen R, Hämeen-Anttila K, et al. A national approach to medicines information research: a systematic review. Res Social Adm Pharm 2018;14:1106-24.

29 Pohjanoksa-Mäntylä M. Medicines information sources and services for consumers: A special focus on the Internet and people with depression [dissertation]. Universityof Helsinki, 2010. http://urn.fi/ URN:ISBN:978-952-10-6128-8

30 Puumalainen I. Development of instruments to measure the quality of patient counselling [dissertation]. University of Kuopio, 2005. http:// urn.fi/URN:ISBN:951-27-0053-0

31 Finlex. Medicines act (Finland) 395/1987. Available: https://www. finlex.fi/fi/laki/ajantasa/1987/ 19870395 [Accessed 10 Dec 2019].

32 Finlex. Decree on the prescription of medicines (Finland) 1088/2010. Available: https://www.finlex.fi/fi/laki/alkup/2010/20101088 [Accessed 10 Dec 2019].

33 Salonen I. National medicines information strategy - medicines related political actions in Finland and in the European Union in the 21 st century to improve the quality and availability of the medicines information directed to the consumers [[master's thesis]]. University of Helsinki, 2010. http://urn.fi/URN:NBN:fife20180115196

34 Department of Health. Better information, better choices, better health - putting information at the centre of health. London: Department of Health, 2004.
35 Young N. National strategies for health and medicines information in the European Union: experiences in the UK and Finland. [report]. University of Helsinki, 2010.

36 Järvinen R, Enlund H, Airaksinen M. Medicines information research in Finland - a report to support the activities of the medicines information network. serial publication Fimea develops, assesses and informs 7/2013. Finnish Medicines Agency, 2013. http://urn.fi/URN: ISBN:978-952-5624-37-3

37 Wagner EH. Chronic disease management: what will it take to improve care for chronic illness? Eff Clin Pract 1998;1:2-4.

38 Wagner EH, Austin BT, Davis C, et al. Improving chronic illness care: translating evidence into action. Health Aff 2001;20:64-78.

39 Nikander J, Tuominen-Thuesen M. National development programme for social welfare and health care (KASTE 2010-2015) external evaluation - final report. Reports and memorandums of the Ministry of Social Affairs and Health, 2016. http://urn.fi/URN:ISBN:978-95200-3800-7

40 Bults M, Beaujean DJMA, Wijkmans CJ, et al. Why did patients with cardiovascular disease in the Netherlands accept $Q$ fever vaccination? Vaccine 2012;30:3369-75

41 Hamrosi KK, Aslani P, Raynor DK. Beyond needs and expectations: identifying the barriers and facilitators to written medicine information provision and use in Australia. Health Expect 2014:17:220-31.

42 Hamrosi KK, Raynor DK, Aslani P. Pharmacist, general practitioner and consumer use of written medicine information in Australia: are they on the same page? Res Social Adm Pharm 2014;10:656-68.

43 Hämeen-Anttila K, Pietilä K, Pylkkänen L, et al. Internet as a source of medicines information (MI) among frequent Internet users. Res Social Adm Pharm 2018;14:758-64.

44 Armitage LC, Kassavou A, Sutton S. Do mobile device apps designed to support medication adherence demonstrate efficacy? A systematic review of randomised controlled trials, with metaanalysis. BMJ Open 2020;10:e032045.

45 Baumgartner PC, Haynes RB, Hersberger KE, et al. A systematic review of medication adherence thresholds dependent of clinical outcomes. Front Pharmacol 2018;9:1290.

46 Conn VS, Ruppar TM, Enriquez M, et al. Medication adherence interventions that target subjects with adherence problems: systematic review and meta-analysis. Res Social Adm Pharm 2016;12:218-46.

47 Conn VS, Ruppar TM, Enriquez M, et al. Patient-Centered outcomes of medication adherence interventions: systematic review and metaanalysis. Value Health 2016;19:277-85.

48 Costa E, Giardini A, Savin M, et al. Interventional tools to improve medication adherence: review of literature. Patient Prefer Adherence 2015;9:1303-14.

49 Torres-Robles A, Wiecek E, Tonin FS, et al. Comparison of interventions to improve long-term medication adherence across different clinical conditions: a systematic review with network metaanalysis. Front Pharmacol 2018;9:1454.

50 Hepler CD, Strand LM. Opportunities and responsibilities in pharmaceutical care. Am J Hosp Pharm 1990;47:533-43.

51 Gale NK, Heath G, Cameron E, et al. Using the framework method for the analysis of qualitative data in multi-disciplinary health research. BMC Med Res Methodol 2013;13:117.

52 Valentijn PP, Schepman SM, Opheij W, et al. Understanding integrated care: a comprehensive conceptual framework based on the integrative functions of primary care. Int $J$ Integr Care 2013;13:e010.

53 O'Brien BC, Harris IB, Beckman TJ, et al. Standards for reporting qualitative research: a synthesis of recommendations. Acad Med 2014;89:1245-51.

54 Elo S, Kääriäinen M, Kanste O, et al. Qualitative content analysis: a focus on trustworthiness. SAGE Open 2014;4.

55 Raskind IG, Shelton RC, Comeau DL, et al. A review of qualitative data analysis practices in health education and health behavior research. Health Educ Behav 2019;46:32-9.

56 Finnish National Board on Research Integrity TENK. The ethical principles of research with human participants and ethical review in the human sciences in Finland. Available: www.tenk.fi/sites/tenk. fi/files/lhmistieteiden_eettisen_ennakkoarvioinnin_ohje_2019.pdf [Accessed 10 Dec 2019].

57 Kallio S, Kumpusalo-Vauhkonen A, Järvensivu T, et al. Towards interprofessional networking in medication management of the aged: current challenges and potential solutions in Finland. Scand J Prim Health Care 2016;34:368-76.

58 Sawan M, Jeon Y-H, Chen TF. Relationship between organizational culture and the use of psychotropic medicines in nursing homes: a systematic integrative review. Drugs Aging 2018;35:189-211. 
59 Sneck S, Saarnio R, Isola A, et al. Medication competency of nurses according to theoretical and drug calculation online exams: a descriptive correlational study. Nurse Educ Today 2016;36:195-201.

60 Sulosaari V, Huupponen R, Torniainen K, et al. Medication education in nursing programmes in Finland - findings from a national survey. Collegian 2014;21:327-35.

61 World Health Organization. Medication without harm: global patient safety challenge on medication safety. World Health Organization, 2017. www.who.int/patientsafety/medication-safety/medicationwithout-harm-brochure/en/

62 Hämeen-Anttila K, Närhi U, Tahvanainen H. Rational pharmacotherapy action plan - final report. Reports and memorandums of the Ministry of Social Affairs and Health, 2018. http://urn.fi/URN:ISBN:978-952-00-3930-1

63 NICE. Medicines optimisation: the safe and effective use of medicines to enable the best possible outcomes. National Institute for Health and Care Excellence, 2015. https://www.nice.org.uk/ guidance/ng5

64 World Health Organization. Health 2020: a European policy framework and strategy for the 21st century. World Health Organization, 2013. http://www.euro.who.int/_data/assets/pdf_ file/0011/199532/Health2020-Long.pdf?ua=1. (Accessed 10 Mar 2020).

65 Airaksinen M, Hämeen-Anttila K, Saastamoinen L. Effective use of research data: research strategy for rational pharmacotherapy 2018-2022. Reports and memorandums of the Ministry of Social Affairs and Health, 2018. http://urn fi/URN:ISBN:978-952-00-3905-9
66 United States Pharmacopeia. Medication counselling behavior guidelines. United States pharmacopeia, 1997.

67 Prime Minister's Office. Finland, a land of solutions - Strategic programme of Prime Minister Juha Sipilä's Government 29 May 2015. Government Publications, 2015. https://vnk.fi/documents/ 10184/1427398/Ratkaisujen+Suomi_EN_YHDISTETTY_netti.pdf/ 8d2e1a66-e24a-4073-8303-ee3127fbfcac/Ratkaisujen+Suomi_EN YHDISTETTY_netti.pdf

68 Finnish Government. Programme of Prime Minister Antti Rinne's Government 6 June 2019. Inclusive and competent Finland - A socially, economically and ecologically sustainable Ssociety. Publications of the Finnish Government, 2019. http://urn.fi/URN: ISBN:978-952-287-760-4

69 Finnish Government. Programme of Prime Minister Sanna Marin's Government 10 December 2019. Inclusive and competent Finland - A socially, economically and ecologically sustainable society. Publications of the Finnish Government, 2019. http://urn.fi/URN: ISBN:978-952-287-811-3

70 Guler S, Hurton S, winn MC, et al. Levels in decision making and techniques for clinicians. Int J Dig Dis 2015;1.

71 Marinker M. Royal Pharmaceutical Society of Great Britain. From compliance to concordance: achieving shared goals in medicine taking. London: Royal Pharmaceutical Society in partnership with Merck Sharp \& Dohme, 1997.

72 Toivo T, Airaksinen M, Dimitrow M, et al. Enhanced coordination of care to reduce medication risks in older home care clients in primary care: a randomized controlled trial. BMC Geriatr 2019;19:332. 